\title{
A Facile Electrochemical Fabrication of Reduced Graphene Oxide-Modified Glassy Carbon Electrode for Simultaneous Detection of Dopamine, Ascorbic Acid, and Uric Acid
}

\author{
Joonhee Yu and Tae Hyun Kim* \\ Department of Chemistry, Soonchunhyang University, Asan 31538, Republic of Korea
}

\begin{abstract}
This paper describes the simple fabrication of an electrode modified with electrochemically reduced graphene oxide (ERGO) for the simultaneous electrocatalytic detection of dopamine (DA), ascorbic acid (AA), and uric acid (UA). ERGO was formed on a glassy carbon (GC) electrode by the reduction of graphene oxide (GO) using linear sweep voltammetry. The ERGO/GC electrode was formed by subjecting a GO solution $\left(1 \mathrm{mg} \mathrm{mL}^{-1}\right.$ in $\left.0.25 \mathrm{M} \mathrm{NaCl}\right)$ to a linear scan from $0 \mathrm{~V}$ to $-1.4 \mathrm{~V}$ at a scan rate of $20 \mathrm{mV} \mathrm{s}^{-1}$. The ERGO/GC electrode was characterized by Raman spectroscopy, Fourier transform infrared spectroscopy, contact angle measurements, electrochemical impedance spectroscopy, and cyclic voltammetry. The electrochemical performance of the ERGO/GC electrode with respect to the detection of DA, AA, and UA in $0.1 \mathrm{M}$ PBS (pH 7.4) was investigated by differential pulse voltammetry (DPV) and amperometry. The ERGO/GC electrode exhibited three well-separated voltammetric peaks and increased oxidation currents during the DPV measurements, thus allowing for the simultaneous and individual detection of DA, AA, and UA. The detection limits for DA, AA, and UA were found to be $0.46,77$, and $0.31 \mu \mathrm{M}$ respectively, using the amperometric i-t curve technique, with the $\mathrm{S} / \mathrm{N}$ ratio being 3 .
\end{abstract}

Keywords : Dopamine, Graphene, Reduced graphene oxide, Electrochemical sensor

Received : 20 July 2017, Accepted: 11 September 2017

\section{Introduction}

Dopamine (DA) is a catecholamine that is considered a key neurotransmitter for the functioning of the central nervous, renal, and hormonal systems of our body [1,2]. Abnormal levels of DA are correlated to various neurological disorders, including schizophrenia, Parkinson's disease, and Huntington's disease $[3,4]$. Therefore, the accurate determination of DA levels can contribute to the diagnosis and treatment of schizophrenia and Parkinson's disease. Since DA is electrochemically active, electrochemical methods are particularly well-suited for the detection of DA owing to their simplicity, fast response rate, low cost, high sensitivity, and suitability for in-situ monitoring $[5,6]$. However, other biological molecules such as

*E-mail address: thkim@sch.ac.kr

DOI: https://doi.org/10.5229/JECST.2017.8.4.274 ascorbic acid (AA) and uric acid (UA) can cause interference during the electrochemical detection of DA $[7,8]$. When present in high concentrations, AA and UA exhibit similar voltammetric responses, making it difficult to detect DA selectively. To overcome this limitation, several protocols have been proposed with the aim of developing chemically modified electrodes (CMEs) based on catalytic nanomaterials $[9,10]$.

Graphene and its related nanomaterials have attracted considerable interest as materials for modifying electrodes to allow for the simultaneous detection of DA, AA, and UA [9,11-15]. Owing to their inherent electrocatalytic nature, graphene-related nanomaterials increase the rate of the sluggish oxidation reaction of AA, leading to the separation of the overlapping signals related to the oxidation of DA and AA. CMEs with graphene-based materials are usually fabricated using reduced graphene oxide 
(RGO). The RGO used in CMEs is mostly obtained by the chemical reduction method $[16,17]$. However, this method typically employs toxic reducing agents, which can contaminate the final product and even cause harm to human health and the environment $[18,19]$. Moreover, electrode modification using RGO is commonly performed using the drop-casting method $[16,17]$, which can lead to variations in the film thickness or internal structure, owing to differences in the evaporation rate across the substrate or because of variations in the solution concentration. Pristine graphene (PG) obtained by the organic saltassisted exfoliation method [15] and electrochemically reduced graphene (ERGO) [20] have been also used to fabricate CMEs for DA sensors. The processes for obtained PG and ERGO are relatively ecofriendly. However, PG- and ERGO-based DA sensors are also prepared by drop-casting. In addition, previously reported ERGO-based DA sensors required several hours of potentiodynamic cycling [20].

Here, we describe the fabrication of an ERGOmodified glassy carbon (GC) electrode for the simultaneous detection of DA, AA, and UA via simple linear sweep voltammetry (LSV). Fig. 1 illustrates the overall procedure for the fabrication of the ERGO/ GC electrode; as can be seen, the method is a facile, rapid, and efficient one. In this method, ERGO is formed on GC by the direct reduction of GO from an aqueous colloidal suspension in the presence of $\mathrm{NaCl}$. The resulting sensor exhibited good selectivity and sensitivity with respect to the simultaneous and individual determination of DA, AA, and UA without requiring any additional treatments.

\section{Experimental}

\subsection{Materials}

Graphite powder, dopamine (DA) hydrochloride,
L-(+)-ascorbic acid (AA), citric acid(CA), uric acid (UA), and potassium hexacyanoferrate $\left(\mathrm{K}_{4}\left[\mathrm{Fe}(\mathrm{CN})_{6}\right]\right)$ were purchased from Sigma-Aldrich Co. (St. Louis, MO, USA). All the other chemicals used such as sodium hydroxide $(\mathrm{NaOH})$, sodium nitrate $\left(\mathrm{NaNO}_{3}\right)$, potassium permanganate $\left(\mathrm{KMnO}_{4}\right)$, sulfuric acid $\left(\mathrm{H}_{2} \mathrm{SO}_{4}\right)$, sodium chloride $(\mathrm{NaCl})$, and potassium chloride were obtained from Duksan Pure Chemicals Co. (Ansan, Korea). All the reagents were analytical grade and were used without further purification. A phosphate buffer solution (PBS, pH 7.0, 0.1 M (mol $\left.\mathrm{L}^{-1}\right)$ ) was prepared by mixing stock solutions of 0.1 $\mathrm{M}$ sodium dihydrogen phosphate $\left(\mathrm{NaH}_{2} \mathrm{PO}_{4}\right)$ and disodium hydrogen phosphate $\left(\mathrm{Na}_{2} \mathrm{HPO}_{4}\right)$. Deionized (DI) water was used throughout the work.

\subsection{Preparation of ERGO/GC electrode}

GO was synthesized from graphite powder according to a modified Hummers method [19]. The synthesized graphite oxide was then mixed with DI water and the dispersion was ultrasonicated for $1 \mathrm{~h}$. Next, $\mathrm{NaCl}$ was added to it to form a homogeneous yellowbrown $\mathrm{GO}$ solution $\left(1 \mathrm{mg} \mathrm{mL}^{-1}\right.$ in $\left.0.25 \mathrm{M} \mathrm{NaCl}\right)$. The electrochemical fabrication of the ERGO/GC electrode was carried out using LSV ( 0 to $-1.4 \mathrm{~V}$ versus $\left.\mathrm{Ag} / \mathrm{AgCl}, 20 \mathrm{mV} \mathrm{s}^{-1}\right)$ in the $\mathrm{GO}$ solution $\left(1 \mathrm{mg} \mathrm{mL}^{-1}\right.$ in $0.25 \mathrm{M} \mathrm{NaCl}$ ) while using a $\mathrm{GC}$ working electrode (Fig. 1). Prior to the electrochemical fabrication of the ERGO/GC electrode, the GC electrode was carefully polished with 0.5 and $0.05 \mu \mathrm{m}$ alumina powder slurries, washed by sonication for $10 \mathrm{~min}$, and subsequently rinsed with DI water several times.

\subsection{Instrumentation}

The electrochemical measurements were performed with a CHI 660D electrochemical workstation (CH Instruments, Inc., Austin, TX, USA). A conventional three-electrode cell was used at room

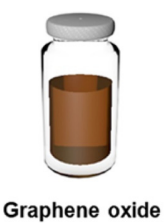

(GO)

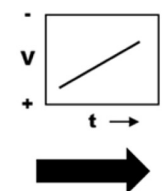

Electrochemical reduction

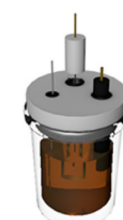

ERGO-modified electrode (ERGO/GC)

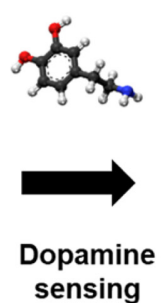

sensing

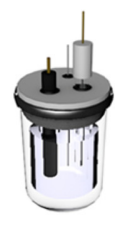

Fig. 1. Schematic diagram of process for fabricating ERGO-modified GC sensor for simultaneous detection of DA, UA, and AA. 
temperature. It consisted of a $\mathrm{Ag} / \mathrm{AgCl}$ (saturated $\mathrm{KCl}$ ) electrode as the reference electrode, a piece of Pt wire as the counter electrode, and a bare GC electrode (3 $\mathrm{mm}$ in diameter) or the $\mathrm{ERGO} / \mathrm{GC}$ electrode as the working electrode. Raman spectroscopy was performed using a EnSpectr R532 Raman spectrometer (Enhanced Spectrometry, Inc., Torrance, USA) with an excitation laser wavelength of $532 \mathrm{~nm}$ and laser power of $30 \mathrm{~mW}$. Contact angle images were taken on a PHOENIX-MINI (SEO Co. Ltd., Korea) system. A P-1 GC plate (BAS Inc., Japan) was used as the substrate for the contact angle analysis. Fourier transform infrared spectroscopy (FTIR) analysis was performed with a NICOLET iS 10 system (Thermo Scientific Korea Ltd.). The morphology of the fabricated electrode was studied using a scanning electron microscopy (SEM) system (JEOL, JSM 5600 LV, Tokyo, Japan).

\section{Results and Discussion}

3.1 Voltammetric behavior of ERGO/GC electrode in mixture of DA, AA, and UA

Fig. 2a shows the typical linear sweep voltammograms recorded during the reduction of $\mathrm{GO}$ on the GC electrode at different scan rates $(10,20,50,80$, and $\left.100 \mathrm{mV} \mathrm{s}^{-1}\right)$. The reduction current peak at approximately $-0.9 \mathrm{~V}$ is due to the electrochemical reduction of some of the oxygen functional groups of GO. The reduction peak potential shifts to a more negative value as the scan rate is increased, with the reduction peak at a scan rate of $100 \mathrm{mV} \mathrm{s}^{-1}$ being broader and distinct. This indicates that the reduction process is irreversible and confirms the direct fabrication of ERGO/GC. GO has various oxygen functional groups, which are likely to show different irreversible redox behaviors. Thus, a relatively fast scan would not suitable for completely reducing the oxygen functional groups with slow redox behaviors, and a low scan rate would be optimal for reducing GO.

The electrochemical behaviors of the $\mathrm{ERGO/GC}$ electrodes formed at the different scan rates with respect to DA, AA, and UA were tested by differential pulse voltammetry (DPV). Fig. $2 b$ shows the DPV curves of the ERGO/GC electrodes with respect to a mixture of DA, AA, and UA in PBS $(0.1 \mathrm{M}, \mathrm{pH}$ 7). The DPV curve of every electrode shows three well-resolved peaks corresponding to DA, AA, and UA. For the ERGO/GC electrodes fabricated at 10 , $20,50,80$, and $100 \mathrm{mV} \mathrm{s}^{-1}$, the differences in the peak potentials of the neighboring waves were 204, $220,164,148$, and $148 \mathrm{mV}$, respectively, in the case of AA and DA and 112, 124, 124, 140, and $128 \mathrm{mV}$, respectively, in the case of DA and UA. Thus, the ERGO/GC electrode formed at $20 \mathrm{mV} \mathrm{s}^{-1}$ exhibited relatively larger voltammetric peak separations and could be used to efficiently discriminate between DA, AA, and UA, based on its voltammetric responses. In addition, the oxidation peaks of the $\mathrm{ERGO/GC} \mathrm{electrode} \mathrm{formed} \mathrm{at} 20 \mathrm{mV} \mathrm{s}^{-1}$ showed the highest-intensity signals. Hence, we used the ERGO/GC electrode fabricated at a scan rate of $20 \mathrm{mV} \mathrm{s}^{-1} \mathrm{~s}$ for the rest of experiments on the detection of DA, AA, and UA. (a)

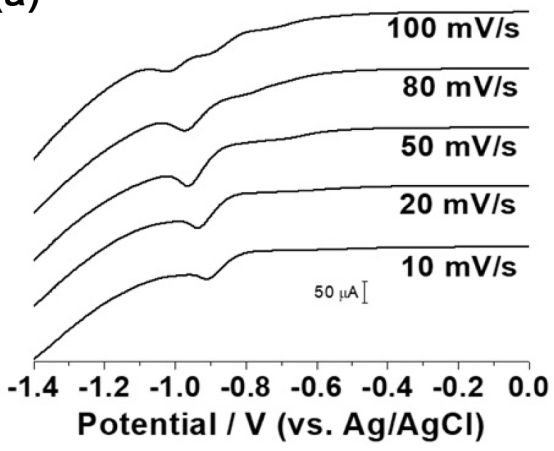

(b)

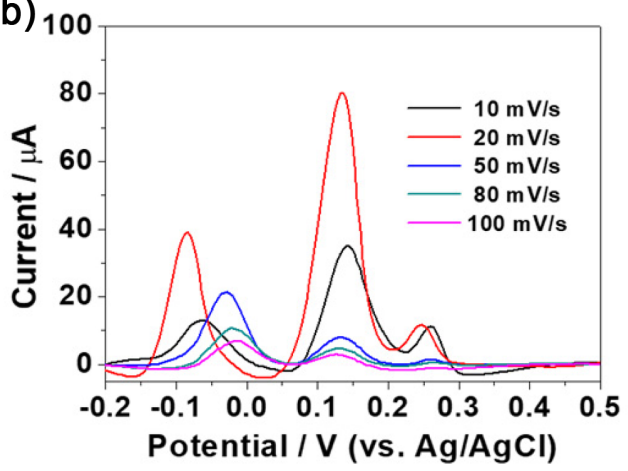

Fig. 2. (a) Linear sweep voltammograms for electrochemical reduction of $\mathrm{GO}$ solution $\left(1 \mathrm{mg} \mathrm{mL}^{-1}\right.$ in $\left.0.25 \mathrm{M} \mathrm{NaCl}\right)$ at scan rates of $10,20,50,80$, and $100 \mathrm{mV} \mathrm{s}^{-1}$. (b) Differential pulse voltammetry (DPV) curves of ERGO/GC electrodes prepared at scan rates of $10,20,50,80$, and $100 \mathrm{mV} \mathrm{s}^{-1}$ in mixed solution of $5 \times 10^{-5} \mathrm{M} \mathrm{DA}, 1 \times 10^{-3} \mathrm{M} \mathrm{AA}$, and $1 \times$ $10^{-5}$ M UA (PBS, $0.1 \mathrm{M}, \mathrm{pH} 7$ ). 


\subsection{Characterization of ERGO/GC electrode}

Raman spectroscopy was employed to investigate the crystal structures of carbon in GO and ERGO. The Raman spectra of GO and ERGO contain the typical D, G, and 2D bands expected in the case of carbonaceous materials; these correspond to the disorder in the $\mathrm{sp}^{2}$ carbon network, the tangential vibrations of the $\mathrm{sp}^{2}$ carbon atoms in the hexagonal planes, and the stacking characteristics of the graphene layers, respectively (Fig. 3a). The ratio of the intensities of the $\mathrm{D}$ and $\mathrm{G}$ bands $\left(\mathrm{I}_{\mathrm{D}} / \mathrm{I}_{\mathrm{G}}\right)$ was used to evaluate the extent of structural disorder; this ratio increased from 1.22 to 1.44 during the reduction of GO to ERGO. This suggests a decrease in the average size of the $\mathrm{sp}^{2}$ carbon network owing to the removal of the oxygen functional groups attached to the GO surface. Fig. $3 \mathrm{~b}$ shows the FTIR spectra of GO and ERGO. The spectrum of GO indicates the presence of hydroxyl, epoxide, and carbonyl functional groups in the GO layer. The broad peak at approximately $3300 \mathrm{~cm}^{-1}$ can be ascribed to the hydroxyl group $(-\mathrm{C}-\mathrm{OH})$. This peak disappeared in the case of ERGO. The peaks at $\sim 1723, \sim 1472,1407$, and $1015 \mathrm{~cm}^{-1}$ correspond to the ketone $(-\mathrm{C}=\mathrm{O})$, carboxyl $(-\mathrm{COOH})$, alkenyl $(-\mathrm{C}=\mathrm{C})$, and alkoxy $(-\mathrm{C}-\mathrm{O})$ groups, respectively. In the case of ERGO, either the intensities of these peaks were

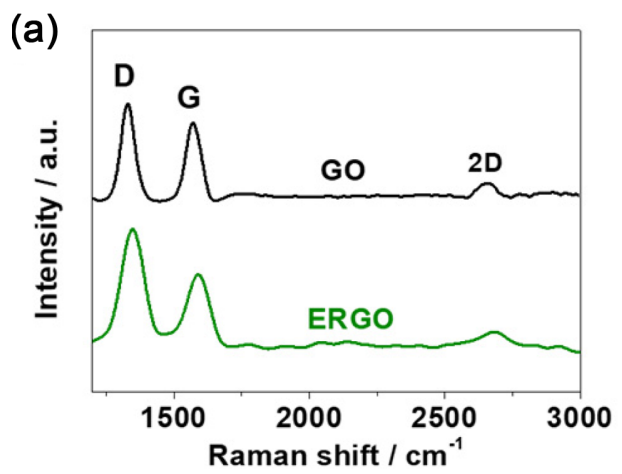

either lower or these peaks were missing. This suggested that de-oxygenation or de-hydroxylation occurred preferentially during the electrochemical reduction process.

To confirm whether the de-oxygenation or dehydroxylation of ERGO had indeed occurred, the changes in the wettability were determined through contact angle measurements. It was expected that deoxygenation during the reduction of GO would result in a more hydrophobic surface. The wetting characteristics of $\mathrm{GC}, \mathrm{GO} / \mathrm{GC}$, and $\mathrm{ERGO} / \mathrm{GC}$ are illustrated in Fig. 4; the average equilibrium static contact angles of $\mathrm{GC}, \mathrm{GO} / \mathrm{GC}$, and $\mathrm{ERGO} / \mathrm{GC}$ are $66^{\circ}, 32^{\circ}$, and $64^{\circ}$ respectively. The GC surface is slightly hydrophobic, probably owing to the polishing treatment or the manufacturing process. On the other hand, the GO/GC surface is hydrophilic, probably owing to the oxygen functional groups grafted onto the GO surface. However, the electrochemical reduction of GO to ERGO induced de-oxygenation, owing to which the hydrophilicity of $\mathrm{GO} / \mathrm{GC}$ changed to hydrophobicity in the case of ERGO/GC.

To investigate the electrochemical properties of the ERGO/GC electrode, cyclic voltammetry (CV) and electrochemical impedance spectroscopy (EIS) measurements were performed using $\mathrm{K}_{4}\left[\mathrm{Fe}(\mathrm{CN})_{6}\right]$ as the

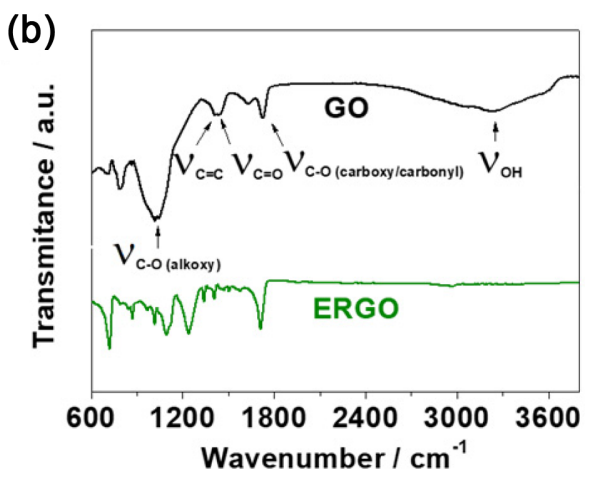

Fig. 3. (a) Raman and (b) FTIR spectra of GO and ERGO.

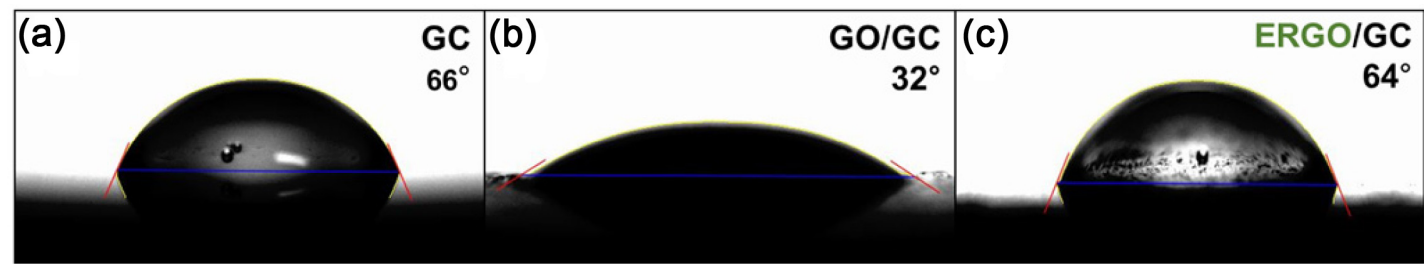

Fig. 4. Contact angles of water droplets on (a) GC, (b) GO/GC, and (c) ERGO/GC. 
electrochemical probe. Fig. 5 shows the voltammetric and impedimetric responses of $\mathrm{GC}, \mathrm{GO} / \mathrm{GC}$, and ERGO/GC in $0.1 \mathrm{M} \mathrm{KCl}$ containing $5 \mathrm{mM}$ $\left[\mathrm{Fe}(\mathrm{CN})_{6}\right]^{4-}$. GC and ERGO/GC exhibit a pair of well-defined redox peaks (Fig. 5a). However, the peak potential difference $\left(\Delta E_{\mathrm{p}}=74 \mathrm{mV}\right)$ in the case of $\mathrm{ERGO} / \mathrm{GC}$ is smaller than that for GC $(107 \mathrm{mV})$, while the peak currents for the former are higher, indicating that the $\mathrm{ERGO/GC}$ electrode exhibited better electrochemical performance. This can be attributed to the electrocatalytic effect and the large effective surface area of the ERGO/GC electrode. The effective surface area of the ERGO/GC electrode, as calculated from the $\mathrm{CV}$ curves obtained using $0.1 \mathrm{M} \mathrm{KCl}$ containing $5 \mathrm{mM}\left[\mathrm{Fe}(\mathrm{CN})_{6}\right]^{4-}$ at different scan rates (Fig. $5 \mathrm{c}$ ), was $0.133 \mathrm{~cm}^{2}$. On the other hand, the peak currents of GO/GC were significantly lower. Further, the $\Delta E_{\mathrm{p}}$ was large at $173 \mathrm{mV}$, because of the presence of the oxygen functional groups on GO. This suggests that the higher conductivity of the ERGO/GC electrode can be ascribed to the reduction of the oxygen functional groups on GO.

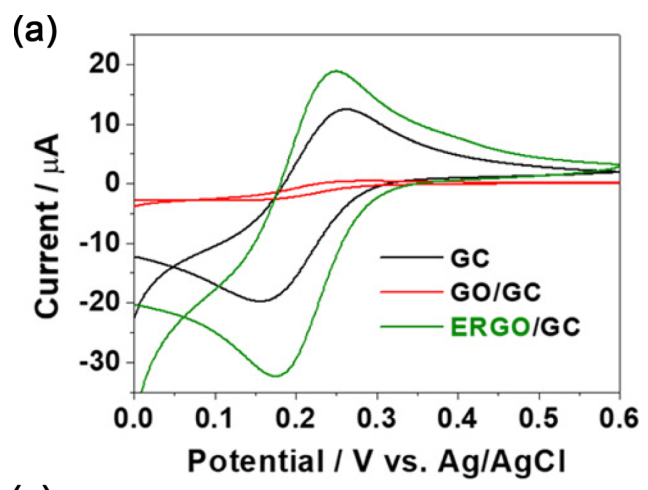

(c)

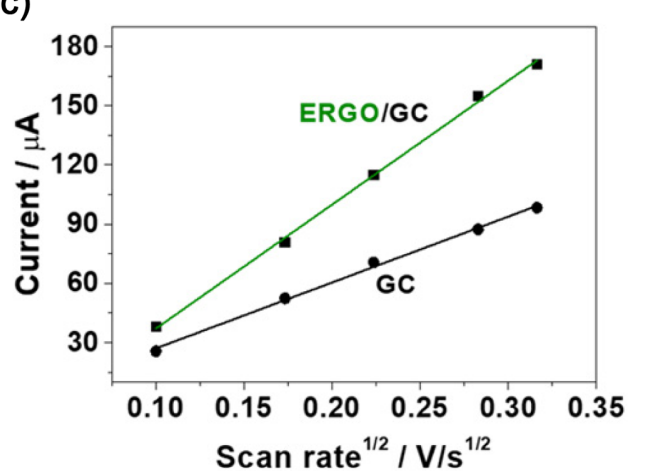

The electron-transfer characteristics of the ERGO/ GC electrode were examined by EIS; the results are shown in Fig. 5b. The charge-transfer resistance $\left(R_{c t}\right)$ of the ERGO/GC electrode was half of that of the bare GC electrode, suggesting that rapid electron transfer occurred on the modified electrode surface. This further confirmed the high electrocatalytic activity of the ERGO/GC electrode. In addition, that the $R_{c t}$ of GO/GC was very high indicated a low electrontransfer rate; this can be attributed to the insulating nature of the numerous oxygen functional groups present on the GO surface. The surface morphology of the ERGO/GC electrode was examined using SEM. As shown in Fig. 5d, the SEM images confirmed the formation of a wrinkled ERGO film on the GC electrode; thus, a highly stable ERGO coating with a high surface area was formed successfully on the GC electrode.

\subsection{Simultaneous detection of DA, AA, and UA}

The DPV analysis of a mixture of DA, AA, and UA using the ERGO/GC electrode suggested that the

(b)

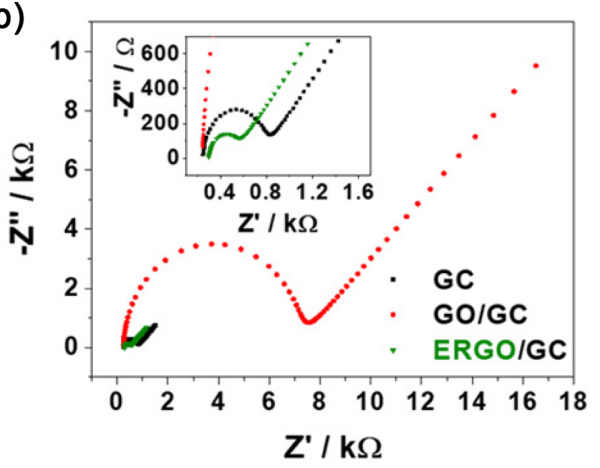

(d)

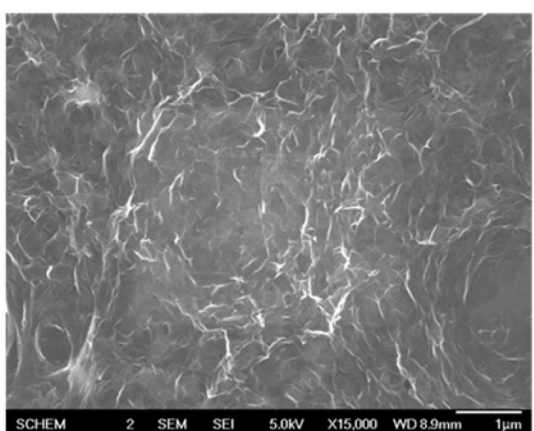

Fig. 5. (a) CV curves obtained at scan rate of $10 \mathrm{mV} \mathrm{s}^{-1}$ and (b) Nyquist plots of GC, GO/GC, and ERGO/GC electrodes in $0.1 \mathrm{M} \mathrm{KCl}$ containing $5 \mathrm{mM}\left[\mathrm{Fe}(\mathrm{CN})_{6}\right]^{4-}$. (c) Relationship between peak current and square root of scan rate for oxidation of GC and ERGO/GC electrodes in $0.1 \mathrm{M} \mathrm{KCl}$ containing $5 \mathrm{mM}\left[\mathrm{Fe}(\mathrm{CN})_{6}\right]^{4-}$. (d) SEM image of ERGO film formed on GC electrode. 

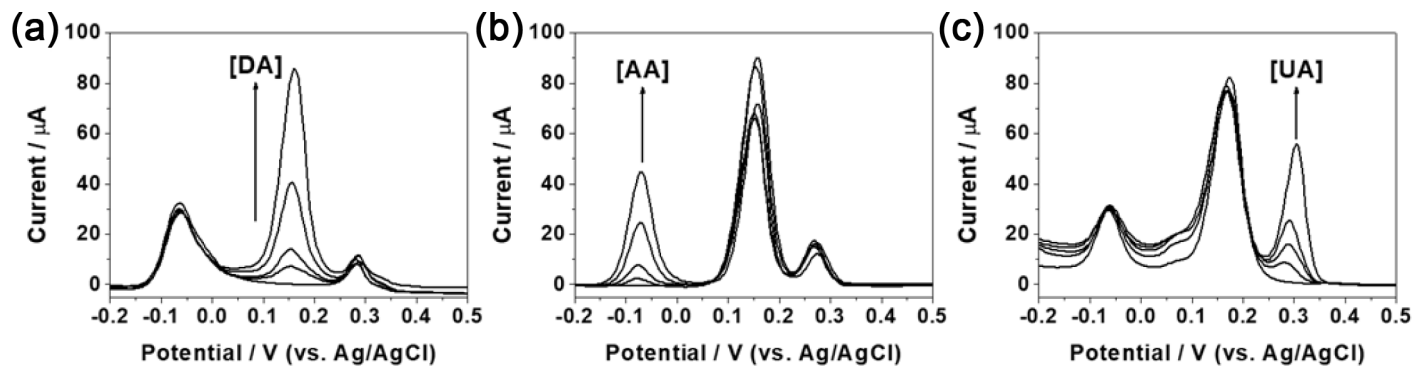

Fig. 6. DPV profiles of ERGO/GC electrode in $0.1 \mathrm{M}$ PBS (pH 7.0) mixed solutions containing (a) $1 \mathrm{mM} \mathrm{AA,} 10 \mu \mathrm{M}$ UA, and DA in different concentrations $(0,10,20$, and $50 \mu \mathrm{M})$; (b) $50 \mu \mathrm{M}$ DA, $10 \mu \mathrm{M} \mathrm{UA}$, and AA in different concentrations $(0,100,200,500$, and $1000 \mu \mathrm{M})$, and (c) $1 \mathrm{mM} \mathrm{AA}, 10 \mu \mathrm{M}$ DA, and UA in different concentrations UA $(0,5,10,20$, and $50 \mu \mathrm{M})$.

Table 1. Comparison of limits of detection (LOD) and sensitivity values with respect to DA, AA, and UA as determined by amperometric and DPV analyses

\begin{tabular}{|c|c|c|c|c|}
\hline & & DA & AA & UA \\
\hline \multirow{3}{*}{ Amperometry } & $\begin{array}{l}\text { Linear regression } \\
\text { equation }\end{array}$ & $\begin{array}{c}\mathrm{i}_{\mathrm{p}}(\mu \mathrm{A})=4.92 \mathrm{E}-08+ \\
0.057 \mathrm{C}(\mu \mathrm{M}) \\
\mathrm{R}^{2}=0.972\end{array}$ & $\begin{array}{c}\mathrm{i}_{\mathrm{p}}(\mu \mathrm{A})=-5.32 \mathrm{E}-08+ \\
3.4 \mathrm{E}-04 \mathrm{C}(\mu \mathrm{M}) \\
\mathrm{R}^{2}=0.995\end{array}$ & $\begin{array}{c}\mathrm{i}_{\mathrm{p}}(\mu \mathrm{A})=-4.11 \mathrm{E}-07+ \\
0.0066 \mathrm{C}(\mu \mathrm{M}) \\
\mathrm{R}^{2}=0.995\end{array}$ \\
\hline & $\begin{array}{l}\text { LOD } \\
(\mu \mathrm{M})\end{array}$ & 0.46 & 76.6 & 0.31 \\
\hline & $\begin{array}{l}\text { Sensitivity } \\
\left(\mu \mathrm{A} \_\mu \mathrm{M}^{-1}\right)\end{array}$ & 0.057 & $3.4 \mathrm{E}-04$ & 0.0066 \\
\hline \multirow{3}{*}{ DPV } & $\begin{array}{l}\text { Linear regression } \\
\text { equation }\end{array}$ & $\begin{array}{c}\mathrm{i}_{\mathrm{p}}(\mu \mathrm{A})=3.80 \mathrm{E}-07+ \\
0.79 \mathrm{C}(\mu \mathrm{M}) \\
\mathrm{R}^{2}=0.999\end{array}$ & $\begin{array}{c}\mathrm{i}_{\mathrm{p}}(\mu \mathrm{A})=2.26 \mathrm{E}-07+ \\
0.049 \mathrm{C}(\mu \mathrm{M}) \\
\mathrm{R}^{2}=0.999\end{array}$ & $\begin{array}{c}\mathrm{i}_{\mathrm{p}}(\mu \mathrm{A})=1.02 \mathrm{E}-06+ \\
0.58 \mathrm{C}(\mu \mathrm{M}) \\
\mathrm{R}^{2}=0.973\end{array}$ \\
\hline & $\begin{array}{l}\mathrm{LOD} \\
(\mu \mathrm{M})\end{array}$ & 2.47 & 119 & 2.35 \\
\hline & $\begin{array}{l}\text { Sensitivity } \\
\left(\mu \mathrm{A} \__{\left.\mu \mathrm{M}^{-1}\right)}\right)\end{array}$ & 0.79 & 0.049 & 0.58 \\
\hline
\end{tabular}

electrode exhibited excellent performance with respect to the simultaneous detection of the three compounds without interference. Fig. 6 illustrates the DPV curves of the electrode in response to DA, AA, and UA; the target molecule was added in increasing concentrations to the mixed solution, while those of the other two analytes were kept constant. As shown in Fig. 6a, the peak current for DA increases with its concentration, with there being no noticeable changes in the peak currents for AA and UA. Similarly, when the concentration of AA or UA was increased while keeping those of the other two species constant, the corresponding peak current increased linearly. These results confirm that the electrode exhibited individual selectivity with respect to DA, AA, and UA, with the interference during the detection measurements being negligible.

\subsection{Amperometric responses to DA, AA, and UA}

To evaluate the analytical performance of the ERGO/GC electrode, chronoamperometric measurements were carried out in 0.1 M PBS ( $\mathrm{pH} 7.0$ ). First, $10 \mathrm{~mL}$ of PBS was placed in the test cell, and the amperometric response of the ERGO/GC electrode was measured at selected working potentials $(0.18$, 0.08 , and $0.32 \mathrm{~V}$ for DA, AA, and UA, respectively) as a stock solution of the target analyte was added at intervals of $100 \mathrm{~s}$. Fig. 7a-c show the amperometric current-time (i-t) plots of the ERGO/GC electrode in response to the successive addition of DA, AA, and $\mathrm{UA}$, respectively, to the PBS solution. The corresponding calibration curves for DA, AA, and UA are displayed in Fig. 7d-f, respectively. The relationship between the target analyte concentration and the corresponding peak current is a linear one. The limits of 

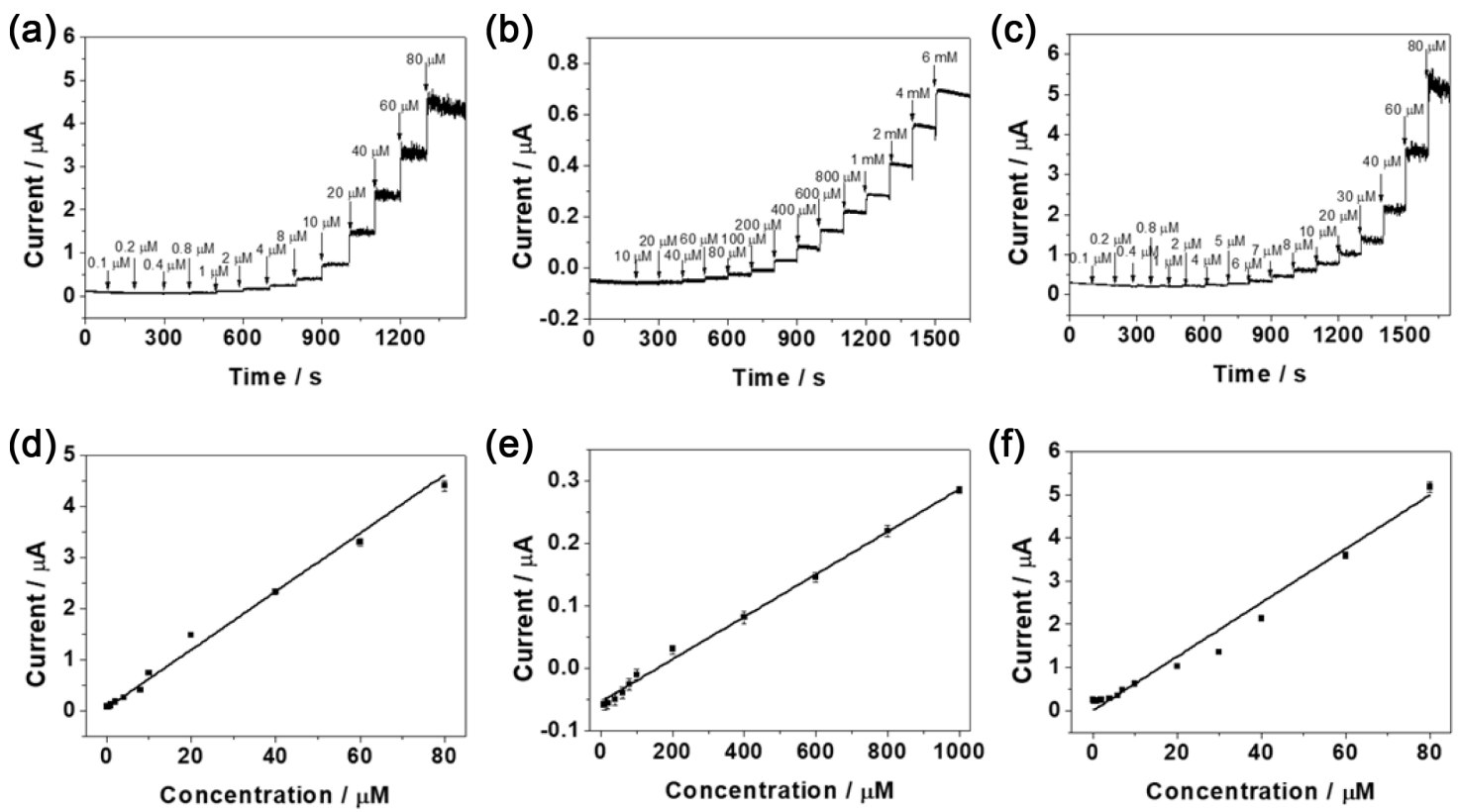

Fig. 7. Amperometric responses of ERGO/GC electrode to successive addition of (a) DA, (b) AA, and (c) UA to PBS (0.1 $\mathrm{M}, \mathrm{pH}$ 7.0) under stirring. Working potentials were $0.18,-0.08$, and $0.32 \mathrm{~V}$ for DA, AA, and UA, respectively. Curves of concentrations of (d) DA, (e) AA, and (f) UA and corresponding oxidation currents are linear.
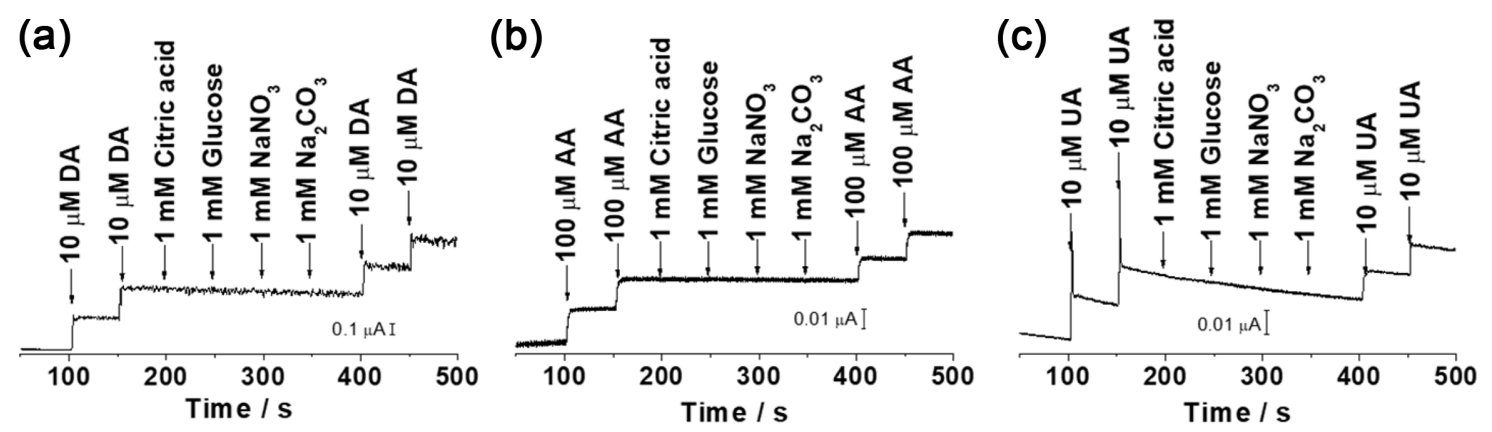

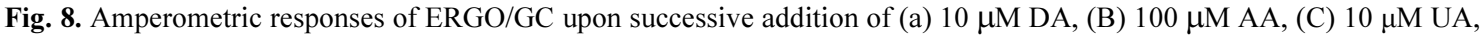
and other chemicals to PBS (0.1 M, pH 7.0) under stirring. Applied potentials for DA, AA, and UA were $0.18,-0.08$, and $0.32 \mathrm{~V}$, respectively.

detection ( $\mathrm{LOD}, \mathrm{S} / \mathrm{N}=3$ ) and sensitivity values with respect to DA, AA, and UA were determined based on the results of amperometric and DPV analyses. The results are shown in Table 1.

\subsection{Interference study}

To investigate the selectivity of the ERGO/GC electrode, we compared its amperometric responses to DA, AA, and UA as well as other biochemical spe- cies and inorganic ions, such as citric acid, glucose, sodium nitrate $\left(\mathrm{NaNO}_{3}\right)$, and sodium carbonate $\left(\mathrm{Na}_{2}\right.$ $\mathrm{CO}_{3}$ ) at different working potentials. As shown in Fig. 8, no interference was observed during the amperometric detection of $10 \mu \mathrm{M}$ DA, $100 \mu \mathrm{M}$ AA, and $10 \mu \mathrm{M}$ UA in the presence of $1 \mathrm{mM}$ citric acid, glucose, sodium nitrate, or sodium carbonate. This result underlines the high selectivity of the ERGO/ GC electrode. 


\section{Conclusions}

We demonstrated a simple electrochemical method for fabricating an ERGO-modified electrode for the simultaneous electrocatalytic sensing of DA, AA, and UA. ERGO was successfully reduced and immobilized simultaneously on the surface of the GC electrode by linear voltammetric scanning. The fabricated ERGO/GC electrode exhibited good electrochemical performance because of its high conductivity, strong electrocatalytic activity, and large effective surface area. DA, AA, and UA could be detected simultaneously and individually by voltammetry using the fabricated ERGO/GC electrode. The analytical performance of the ERGO/GC electrode was also analyzed. The results indicate that the fabricated electrode is a promising platform for fabricating simple and efficient electrochemical biosensors.

\section{Acknowledgements}

This work (Grants No. C0483053) was supported by Business for Cooperative R\&D between Industry, Academy, and Research Institute funded Korea Small and Medium Business Administration in 2017. This work was also supported by the Soonchunhyang University Research Fund.

\section{References}

[1] K. C. Berridge, T. E. Robinson, Brain Res. Rev. 1998, 28, 309-369.

[2] P. Seeman, Pharmacol. Rev. 1980, 32(3), 229-313.

[3] K. L. Davis, R. S. Kahn, others, Am. J. Psychiatry 1991,
148(11), 1474

[4] H. Bernheimer, W. Birkmayer, O. Hornykiewicz, K. Jellinger, F. Seitelberger, J. Neurol. Sci. 1973, 20(4), 415-455.

[5] B. J. Venton, R. M. Wightman, Anal. Chem. 2003, 75, 414 A-421 A.

[6] C. D. Blaha, A. G. Phillips, J. Neurosci. Methods 1990, 34(1), 125-133.

[7] F. Gonon, M. Buda, R. Cespuglio, M. Jouvet, J.-F. Pujol, Nature 1980, 286(5776), 902-904.

[8] R. D. O’Neill, Analyst 1994, 119(5), 767-779.

[9] M. Sajid, M. K. Nazal, M. Mansha, A. Alsharaa, S. M. S. Jillani, C. Basheer, TrAC Trends Anal. Chem. 2016, $76,15-29$

[10] J.-W. Oh, Y. W. Yoon, J. Heo, J. Yu, H. Kim, T. H. Kim, Talanta 2016, 147, 453-459.

[11] A. Pandikumar, G. T. S. How, T. Peik See, F. Saiha Omar, S. Jayabal, K. Zangeneh Kamali, N. Yusoff, A. Jamil, R. Ramaraj, S. Abraham John, et al., RSC Adv. 2014, 4(108), 63296-63323.

[12] Z.-H. Sheng, X.-Q. Zheng, J.-Y. Xu, W.-J. Bao, F.-B. Wang, X.-H. Xia, Biosens. Bioelectron. 2012, 34(1), 125-131.

[13] M. Pumera, A. Ambrosi, A. Bonanni, E. L. K. Chng, H. L. Poh, TrAC Trends Anal. Chem. 2010, 29(9), 954-965.

[14] M. M. I. Khan, A.-M. J. Haque, K. Kim, J. Electroanal. Chem. 2013, 700, 54-59.

[15] S. Qi, B. Zhao, H. Tang, X. Jiang, Electrochimica Acta 2015, 161, 395-402.

[16] M. Zhou, Y. Zhai, S. Dong, Anal. Chem. 2009, 81(14), 5603-5613.

[17] V. Mani, A. P. Periasamy, S.-M. Chen, Electrochem. Commun. 2012, 17, 75-78.

[18] S. Pei, H.-M. Cheng, Carbon 2012, 50(9), 3210-3228.

[19] D. Chen, H. Feng, J. Li, Chem. Rev. 2012, 112(11), 6027-6053.

[20] L. Yang, D. Liu, J. Huang, T. You, Sens. Actuators B Chem. 2014, 193, 166-172. 